\title{
PENGARUH UNCERTAINTY TERHADAP KEBIJAKAN TRADE CREDIT PERUSAHAAN INDONESIA
}

\author{
Febrianto $^{1)}$, Rita Juliana ${ }^{2) *}$ \\ ${ }^{1), 2)}$ Program Studi Manajemen Fakultas Ekonomi dan Bisnis, Universitas Pelita Harapan \\ Email : rita.juliana@uph.edu
}

Diterima 11 Februari 2021 / Disetujui 26 Juli 2021

\begin{abstract}
Uncertainty seems to be the root of prolonged recession period problem and it increases researcher concern regarding its effect to the economy. During high uncertainty period, information is not clear and affect firm's decision maker regarding their investment, capital structure and also trade credit policy. In this paper, we aim to find the effect of uncertainty to firm's trade credit policy. Uncertainty is argued to increase firm's credit risk and thus, firm should adjust their trade credit policy to survive. Our sample includes non-financial listed firms in Indonesia Stock Exchange (IDX), with observation period from 2006 Q1 to 2019 Q4. The financial data used to construct the variables are obtained from the S\&P Capital $I Q$ database. The methodology used is fixed effect panel data regression. This study utilized uncertainty measurement developed by Ahir et al. (2018), that is the world uncertainty index (WUI). Using total of 12,773 firm-quarter observations, our result show that uncertainty indeed caused firms to adjust their trade credit policy. Uncertainty caused higher cost of capital, as consequences firms decide to tighten their credit policy to its customer and decrease their payables to the supplier as precautionary to avoid future financial distress.
\end{abstract}

Keywords: Uncertainty, trade credit policy, receivable days, payable days

\begin{abstract}
ABSTRAK : Ketidakpastian dianggap menjadi akar dari masalah periode resesi yang panjang dan hal ini meningkatkan kekhawatiran dari para peneliti mengenai efeknya terhadap ekonomi. Pada keadaan ketidakpastian yang tinggi, informasi menjadi tidak jelas dan mempengaruhi pengambil keputusan didalam perusahaan mengenai kebijakan investasi, struktur modal dan juga kredit dagang. Pada penelitian ini, kami bertujuan untuk menemukan efek dari ketidakpastian pada kebijakan kredit dagang perusahaan. Ketidakpastian dikatakan dapat meningkatkan resiko kredit perusahaan dan sehingga, perusahaan perlu menyesuaikan kebijakan kredit dagang mereka untuk dapat bertahan. Sampel penelitian ini termasuk perusahaan non keuangan yang terdaftar pada bursa efek Indonesia (BEI), dengan periode observasi dari 2006 kuartal 1 hingga 2019 kuartal 4. Data keuangan yang digunakan untuk membentuk variabel pebelitian diambil dari the $S \& P$ Capital IQ database. Metodologi yang digunakan adalah regresi data panel fixed effect. Penelitian ini menggunakan ukuran ketidakpastian yang dikembangkan oleh Ahir et al.(2018), yaitu the world uncertainty index (WUI). Dengan menggunakan total observasi sebanyak 12.773 perusahaan-kuartal, hasil yang didapatkan menunjukkan bahwa ketidakpastian mennyebabkan perusahaan untuk melakukan penyesuaian pada kebijakan kredit dagangnya. Ketidakpastian meningkatkan biaya modal dan sebagai akibatnya perusahaan memutuskan untuk memperketat kebijkan kredit kepada pembeli dan menurunkan hutang dagangnya pada pemasok sebagai tindakan berhati-hati untuk menghindari kesulitan keuangan dimasa depan.
\end{abstract}

Kata Kunci: Ketidakpastian, kebijakan kredit dagang, receivable days, payable days

\section{Pendahuluan}

Uncertainty menjadi salah satu topik yang dibahas didalam dunia bisnis. Menurut Kozeniauskas et al. (2018), uncertainty yang tinggi secara makro dan global berperan dalam resesi 2007 hingga 2009. Ketidakpastian informasi menghambat pertumbuhan negara berkembang, dan menyebabkan ketidakpastian dalam kebijakan moneter negara maju. Penelitian 
mengenai uncertainty mulai menarik perhatian para peneliti setelah terjadinya krisis pada 2008. Menurut Ozturk \& Sheng, (2018) uncertainty yang tinggi merupakan salah satu faktor terjadinya resesi pada tahun 2007 hingga 2009, dan juga merupakan faktor penghambat pemulihan ekonomi. Didukung oleh Bloom et al. (2018) yang menyatakan bahwa uncertainty berpengaruh terhadap penurunan GDP sebesar $2.5 \%$. Pada periode dengan uncertainty tinggi, perusahaan akan resah mengenai harga aset, gaji, dan kinerja perusahaan yang akan mendatang (Leahy \& Whited, 1996).Perusahaan akan lebih waspada dalam mengambil tindakan dan menghindari risiko. Dalam kondisi ketidakpastian yang tinggi, perusahaan cenderung "wait and see", yaitu menunggu informasi baru yang dapat diperoleh. Investasi yang akan dilakukan perusahaan tentunya menurun, seperti mengurangi tingkat produksi dan tenaga kerja (Gulen \& Ion, 2016). Penurunan tersebut terjadi karena perusahaan cenderung lebih berhati-hati dan mengurangi investasi seiring dengan menunggu keadaan informasi yang lebih jelas.

Selain pada investasi, uncertainty dapat memengaruhi keputusan perusahaan lainnya. Penelitian ini memberikan kontribusi kepada literatur uncertainty dengan melihat apakah uncertainty memiliki pengaruh pada kebijakan trade credit yang diambil perusahaan. Trade Credit dipandang sebagai salah satu faktor yang penting dalam kegiatan bisnis pada perusahaan. Cheng dan Pike (2003) mengatakan bahwa mayoritas perusahaan dalam ekonomi yang maju sangat bergantung pada penggunaan trade credit. Trade Credit digunakan ketika penjual menyediakan produk ataupun jasa kepada pembeli dan memperbolehkan penundaan pembayaran untuk produknya (Mian \& Smith, 1992). Berdasarkan penelitian yang telah dilakukan, terdapat beberapa manfaat bagi perusahaan untuk melakukan trade credit, salah satunya yaitu peningkatan efisiensi. Berdasarkan kebijakan trade credit yang diberikan perusahaan, pembayaran dilakukan dalam satu kali transaksi untuk keseluruhan produk yang telah terkirim dalam jangka waktu yang telah disepakati. Hal tersebut akan menguntungkan bagi perusahaan, karena dapat menghemat biaya transaksi jika dibandingkan melakukan pembayaran setiap penerimaan produk (Białek-Jaworska \& Nehrebecka, 2016). Maka dari itu, trade credit akan memudahkan penyaluran produk dari pihak penjual kepada pihak pembeli, dan bersifat fundamental dalam supply chain (Cheng \& Pike, 2003). Namun, kebijakan perusahaan dalam pemberian trade credit dapat berubah pada masa uncertainty yang tinggi. Menurut survei yang dilakukan oleh The International Trade and Forfaiting Association (ITFA), ketidakpastian yang diakibatkan oleh Brexit (Britain Exit) menyebabakan perusahaan di Inggris untuk mempertimbangkan perubahan pada kebijakan trade credit mereka. Hal ini diakibatkan karena akan banyaknya kebijakan pemerintah dan peraturanperaturan yang akan berubah oleh karena Brexit.

Terdapat 2 kemungkinan bagaimana uncertainty dapat berdampak terhadap trade credit. Pertama, Jory et al. (2020) menjelaskan bahwa uncertainty yang tinggi dapat berpengaruh terhadap tingkat produksi perusahaan, dimana perusahaan akan mengurangi produksi yang akan berpengaruh terhadap ketersediaan produk. Gulen \& Ion, (2016) juga menemukan bahwa uncertainty memiliki hubungan yang negatif dengan tingkat investasi perusahaan, karena uncertainty menyebabkan fluktuasi pada harga aset serta permintaan pasar, maka perusahaan akan memilih untuk menyediakan kas cadangan lebih seiring meningkatnya risiko. Hal tersebut akan berpengaruh terhadap kemampuan pihak penjual untuk memberikan trade credit kepada pembeli dan mengurangi daya penawaran yang mampu diberikan oleh pihak penjual.

Kedua, dikarenakan trade credit dapat dikatakan sebagai pembiayaan pihak penjual terhadap pihak pembeli, hal ini menjadi pertimbangan perusahaan untuk mengubah kebijakan trade credit yang telah diberikan. Perubahan yang dapat dilakukan pihak penjual seperti memperpendek jangka waktu pembayaran yang dilakukan untuk mengurangi risiko gagal bayar dan meningkatkan pemasukan kas perusahaan. $\mathrm{Xu}$, (2020) menjelaskan bahwa uncertainty akan berdampak terhadap cost of capital perusahaan, jika uncertainty meningkat maka cost of capital juga akan meningkat. 
Peningkatan cost of capital mempersulit perusahaan untuk mendapatkan pendanaan dari luar yang akan digunakan untuk investasi dan mengurangi profitabilitas investasi tersebut. Tingginya cost of capital meningkatkan kekhawatiran perusahaan akan tingkat solvabilitas dalam membayar kewajibannya dimasa depan. Sehingga pada akhirnya, perusahaan akan berpikir lagi dalam keputusan memberikan kredit kepada pelanggannya.

Berdasarkan oleh latar belakang yang telah dijelaskan diatas, penelitian ini bertujuan untuk mengetahui apakah uncertainty dapat mempengaruhi kebijakan trade credit yang diberikan perusahaan. Peneliti akan melakukan analisa pada trade receivables, dan trade payable perusahaan publik di Indonesia. Penting bagi perusahaan untuk dapat mengetahui bagaimana uncertainty dapat memengaruhi kebijakan trade credit perusahaan. Menurut Petersen dan Rajan (1997), pemberian trade credit kepada pembeli, diiringi dengan pengelolaan inventoris yang baik membuat perusahaan menjadi lebih efektif dalam menyalurkan produk kepada pembeli dan dapat menghemat biaya gudang (carrying cost/ warehousing cost). Dengan demikian, melalui penelitian ini diharapkan dapat memberikan gambaran dengan perusahaan perlu meningkatkan pemahaman perusahaan mengenai pengelolaan kebijakan trade credit sehingga perusahaan dapat menghasilkan nilai tambah bagi pemangku kepentingan perusahaan.

\section{Pengembangan Hipotesis}

Cheng \& Pike, (2003) menyatakan bahwa perusahaan akan lebih efisien dengan trade credit karena melakukan pembayaran satu kali dalam jangka waktu yang ditentukan, dibandingkan pembayaran saat setiap pengiriman. Dalam penelitian sebelumnya, dijelaskan bahwa perusahaan cenderung akan memberikan trade credit karena menguntungkan pihak pembeli dan penjual. Pada saat periode uncertainty yang tinggi, permintaan pasar akan berkurang, sehingga hal ini dapat menyebabkan manfaat trade credit bagi perusahaan berkurang.

Uncertainty merupakan risiko yang timbul atas ketidakpastian kebijakan moneter, fiskal, ataupun regulasi pada tingkatan makro
(Jory et al., 2020). Penelitian yang dilakukan oleh Gulen \& Ion, (2016) menemukan bahwa periode uncertainty yang tinggi akan menyebabkan penurunan pada investasi perusahaan. Pengurangan investasi seperti mengurangi produksi dan ketersediaan produk, ataupun perubahan credit policy berupaya untuk mengurangi risiko dan perusahaan cenderung melakukan "wait and see" untuk mendapatkan informasi baru. Phan et al., (2018) menemukan bahwa perusahaan akan meningkatkan kas ketika uncertainty tinggi. Maka dari itu, daya tawar pembeli dan penjual akan berkurang, dan likuiditas menjadi suatu pertimbangan dalam pemberian trade credit.

Selain itu, dalam upaya meminimalisir risiko terjadinya bad debt expenses, pihak penjual akan menuntut pembayaran yang lebih cepat ataupun biaya pemberian credit yang lebih tinggi untuk memastikan likuiditas serta arus kas. Pihak pembeli akan kesulitan untuk mendapatkan pembiayaan eksternal sebagai modal kerja dan borrowing cost akan meningkat ( $\mathrm{Xu}, 2020)$. Adapun $\mathrm{Li}$ dan $\mathrm{Su}$ (2020) yang menemukan bahwa uncertainty memiliki hubungan negative dengan debt maturity dan berhubungan positif dengan cost of debt. Berdasarkan dari argument-argumen diatas, maka hipotesis penelitian ini adalah sebagai berikut:

H1 : Uncertainty berpengaruh terhadap kebijakan trade credit perusahaan.

\section{Metode Penelitian}

Sampel dari penelitian ini adalah perusahaan-perusahaan yang telah terdaftar di Bursa Efek Indonesia (BEI). Perusahaan yang dikeluarkan dari sampel penelitian antara lain perusahaan dengan kriteria sebagai berikut:

a. Perusahaan yang tidak memiliki data laporan keuangan yang dibutuhkan.

b. Perusahaan dengan nilai aset, kapitalisasi pasar, dan penjualan yang negatif.

c. Perusahaan di industri keuangan

Data laporan keuangan diperoleh dari database S\&P Capital IQ dan jangka waktu yang digunakan dari tahun 2006 Q1 hingga 2019 Q4. Sedangkan untuk ukuran uncertainty yang digunakan diambil dari https://www.policyuncertainty.com/ yang dikembangkan oleh Ahir et al. (2018). 
Ukuran uncertainty ini merupakan index yang dibentuk dengan menghitung kata "uncertainty" pada laporan Economist Intelligence Unit (EIU) country. Laporan ini secara umum membahas keadaan negara dalam bidang ekonomi, politik dan keuangan. semakin tinggi angka yang digunakan

\section{Model Empiris}

Untuk menguji pengaruh Uncertainty terhadap kebijakan trade credit perusahaan, maka peneliti menggunakan model regresi sebagai berikut :

TRADECREDIT $T_{i, t}$

$$
\begin{aligned}
& =\alpha_{i}+\beta_{1} U_{t-1}+\beta_{2} \text { GROSSMARGIN }_{i,-1-1}+\beta_{3} \text { ASSETTO }_{i, t-1} \\
& +\beta_{4} \operatorname{RRECOLL}_{i, t-1}+\beta_{5} \text { CASH }_{i, t-1}+\beta_{6} \text { SHTDEBT }_{i, t-1}+\varepsilon_{i, t}
\end{aligned}
$$

Dimana:

$$
\begin{array}{ll}
\text { TRADECREDIT } & =\text { Kebijakan trade credit } \\
U & =\text { Ketidakpastian } \\
\text { GROSSMARGIN } & =\text { Keuntungan kotor } \\
\text { ASSETTO } & =\text { Asset turnover } \\
\text { FREECOLL } & =\text { Kolateral bebas } \\
C A S H & =\text { Kas } \\
\text { SHTDEBT } & =\text { hutang jangka pendek }
\end{array}
$$

\section{Operasionalisasi Variabel}

Tradecredit

Kebijakan kredit dagang adalah variabel dependen pada penelitian ini. Kebijakan kredit dagang dianalisis dengan menggunakan dua variabel yaitu receivable days dan payable days, yang dihitung dengan menggunakan rumus dibawah ini:

$$
\begin{aligned}
\text { Receivables days } & =\frac{\text { receivables }}{\text { Sales }} \times 90 \\
\text { Payables days } & =\frac{\text { payables }}{\text { Sales }} \times 90
\end{aligned}
$$

\section{Uncertainty}

Pengukuran ketidakpastian pada penelitian ini menggunakan ukuran yang dikembangkan oleh Ahir et al. (2018) yaitu World uncertainty index (WUI) yang merupakan ketidakpastian pada level dunia, yaitu untuk menggambarkan ketidakpastian yang dialami negara di dunia secara keseluruhan. Selain itu digunakan juga uncertainty pada level negara Indonesia, yang menggambarkan ketidakpastian yang dialami spesifik di negara Indonesia. Penggunaan dua ukuran ketidakpastiaan ini untuk melihat apakah perusahaan lebih sensitif pada ketidakpastian yang lebih umum dialami banyak negara atau spesifik di Indonesia. Kedua ukuran ini kemudian diambil logaritma naturalnya.

\section{Variabel Kontrol}

Dibawah ini adalah rumus dari variabel control yang digunakan pada model empiris (Jory et al., 2020; Xu, 2020).

$$
\text { GROSSMARGIN }=\frac{\text { Sales }- \text { Cost of Goods Sold }}{\text { Sales }}
$$

Asset turnover $=\frac{\text { Total Sales }}{\text { Total Asset }}$

FREE COLL $=\frac{\text { Net fixed asset }- \text { Long term debt }}{\text { Total Asset }}$

CASH $=\frac{\text { Total Cash }}{\text { Total Asset }}$

SHORT TERM DEBT $=\frac{\text { Short term debt }}{\text { Total Asset }}$

\section{Hasil Dan Pembahasan \\ Deskriptif Statistik}

Tabel 1 menunjukkan deskriptif statistik variabel penelitian ini. Variable pada tabel 1 merupakan variabel yang telah di winsor dengan pada level $1 \%$. Winsorisasi dilakukan untuk mengurangi efek outlier. Terlihat pada deskriptif statistik pada tabel 1 tidak memperlihatkan adanya kejanggalan dalam data sehingga peneliti dapat melanjutkan ke analisis regresi untuk pengambilan keputusan hipotesis. 
Tabel 1. Deskriptif Statistik

\begin{tabular}{lrrrrr}
\hline Variable & Obs & Mean & Std. Dev. & Min & Max \\
\hline GROSSMARGIN & 12773 & .311 & .201 & .01 & .877 \\
ASSETTO & 12773 & .336 & .32 & .005 & 1.866 \\
FREECOLL & 12773 & .263 & .26 & -.464 & .823 \\
CASH & 12773 & .136 & .134 & .002 & .636 \\
SHORTDEBT & 12773 & .385 & .322 & .017 & 1.855 \\
WUI & 12773 & 9.957 & .374 & 9.111 & 10.873 \\
NORMUNCT & 12773 & .019 & .135 & 0 & 1 \\
REC_DAYS & 12773 & 76.608 & 89.364 & 0 & 497 \\
PAY_DAYS & 12773 & 284.912 & 538.383 & 7 & 4540 \\
\hline
\end{tabular}

Sumber: data diolah penulis

\section{Hasil Regresi}

Tabel 2 menunjukkan hasil regresi penelitian ini. Regresi yang dilakukan adalah regresi panel data fixed effect dengan Driscroll-Kraay standard errors yang digunakan untuk mengatasi masalah asumsi klasik seperti heteroskedastisitas, autokorelasi dan cross-dependence (Hoechle, 2007).

Pada kolom 1 dan 2 adalah hasil regresi untuk melihat pengaruh ketidakpastian pada receivables days, sedangkan kolom 3 dan 4 adalah hasil regresi untuk melihat pengaruh ketidakpastian pada payables days. Pada penelitian ini kami menggunakan dua ukuran ketidakpastian yaitu WUI sebagai ketidakpastian level dunia terlihat pada kolom 1 dan 3, sedangkan NORMUNCT menunjukkan ketidakpastian level Indonesia terlihat pada kolom 2 dan 4 .

Pada kolom 1, menunjukkan bahwa WUI berpengaruh negatif pada receivable days. Hal ini menunjukkan bahwa perusahaann akan memperketat pemberian kredit kepada pembeli pada saat periode ketidakpastian tinggi. Pada kolom 2, menunjukkan bahwa NORMUNCT tidak berpengaruh signifikan pada receivable days. Hasil tersebut menunjukkan bahwa ketidakpastian pada level dunia menjadi lebih penting dibandingkan dengan ketidakpastian level Indonesia untuk perusahaan dalam menentukkan pemberian kredit kepada customer mereka.

Selanjutnya, pada kolom 3, dapat terlihat bahwa ketidakpastian level dunia (WUI) tidak memberikan pengaruh signifikan pada payables days. Jika dibandingkan dengan hasil pada kolom 4, NORMUNCT berpengaruh negative signifikan pada payables days. Hal ini menunjukkan keterbalikan dengan hasil di kolom 1 dan 2, bahwa WUI memberikan pengaruh pada kebijakan pemberian piutang dan NORMUNCT (ketidakpastian level Indonesia) memberikan pengaruh pada kebijakan menggunakan hutang usaha.

Hasil yang ditunjukkan pada variabel kontrol (GROSSMARGIN, ASSETTO, FREECOLL, CASH, dan SHORT DEBT) menunjukkan hasil yang sesuai dengan penelitian-penelitian terdahulu (Jory et al., 2020; Xu, 2020). Variabel kontrol dimasukkan kedalam model empiris agar peneliti dapat lebih akurat melihat pengaruh dari variabel ketidakpastian pada receivable days dan payable days.

Hasil penelitian ini sesuai dengan penelitian sebelumnya, yaitu umumnya perusahaan cenderung mengurangi permintaan akan barang pada saat ketidakpastian tinggi, sehingga hal ini mengurangi persedian dan lebih memilih untuk memegang candangan kas dibandingkan memberikan kredit kepada pelanggannya. Selain itu, keadaan ketidakpastian tinggi menyebabkan masalah informasi asimetris menjadi tinggi, sehingga biaya modal perusahaan juga meningkat. Untuk menghindari masalah kendala keuangan dimasa depan, perusahaan memutuskan untuk mengurangi penggunaan hutang dagang. Seperti yang diketahui bahwa hutang dagang jangka pendek yang terlalu tinggi dapat meningkatkan resiko kebangkrutan (Jory et al., 2020).

Sebagai kesimpulan, penelitian ini menemukan bahwa terdapat perbedaan pada hasil ketidakpastian level dunia (WUI) dan level negara Indonesia (NORMUNCT). Perbedaan ini belum dapat dipastikan penyebabnya, dan peneliti meninggalkan pertanyaan ini untuk peneliti selanjutnya 
Tabel 2. Hasil Regresi uncertainty pada Trade Credit

\begin{tabular}{|c|c|c|c|c|}
\hline & \multicolumn{4}{|c|}{ Variabel Dependen } \\
\hline & & REC_DAYS & & PAY_DAYS \\
\hline & (1) & (2) & (3) & (4) \\
\hline WUI & $\begin{array}{c}-1.913 * * \\
(.92)\end{array}$ & & $\begin{array}{c}-1.364 \\
(22.444)\end{array}$ & \\
\hline NORMUNCT & & $\begin{array}{l}-1.315 \\
(1.051)\end{array}$ & & $\begin{array}{c}-56.029 * * * \\
(13.541)\end{array}$ \\
\hline GROSSMARGIN & $\begin{array}{c}7.249 \\
(4.895)\end{array}$ & $\begin{array}{c}7.242 \\
(4.856)\end{array}$ & $\begin{array}{l}-116.797 \\
(83.113)\end{array}$ & $\begin{array}{l}-115.677 \\
(82.873)\end{array}$ \\
\hline ASSETTO & $\begin{array}{c}59.128 * * * \\
(8.083)\end{array}$ & $\begin{array}{c}59.439 * * * \\
(8.158)\end{array}$ & $\begin{array}{c}-133.191 * * \\
(58.692)\end{array}$ & $\begin{array}{c}-131.111 * * \\
(57.283)\end{array}$ \\
\hline FREECOLL & $\begin{array}{c}-17.157 * * * \\
(4.848)\end{array}$ & $\begin{array}{c}-17.283^{* * *} * \\
(4.881)\end{array}$ & $\begin{array}{c}-242.263 * * * \\
(40.002)\end{array}$ & $\begin{array}{c}-241.904 * * * \\
(40.124)\end{array}$ \\
\hline CASH & $\begin{array}{l}-10.616 \\
(7.659)\end{array}$ & $\begin{array}{c}-10.458 \\
(7.65)\end{array}$ & $\begin{array}{c}60.078 \\
(66.193)\end{array}$ & $\begin{array}{c}62.202 \\
(66.335)\end{array}$ \\
\hline SHORTDEBT & $\begin{array}{c}60.266^{* * * *} \\
(7.804)\end{array}$ & $\begin{array}{c}60.458 * * * \\
(7.817)\end{array}$ & $\begin{array}{c}115.128 * * \\
(51.721)\end{array}$ & $\begin{array}{c}115.286 * * \\
(53.187)\end{array}$ \\
\hline _cons & $\begin{array}{c}56.36 * * * \\
(10.7)\end{array}$ & $\begin{array}{c}37.17 * * * \\
(4.891)\end{array}$ & $\begin{array}{l}390.704 * \\
(208.928)\end{array}$ & $\begin{array}{c}376.686 * * * \\
(35.157)\end{array}$ \\
\hline Observations & 12773 & 12773 & 12773 & 12773 \\
\hline Pseudo $\mathrm{R}^{2}$ & 0.172 & 0.172 & 0.089 & 0.092 \\
\hline P-value (F-stat) & 0.0000 & 0.0000 & 0.0000 & 0.0000 \\
\hline
\end{tabular}

Sumber : Hasil Pengolahan Data Penulis

\section{Simpulan}

Ketidakpastian menjadi salah satu penyebab utama krisis perekonomian sehingga perlu dipertimbangkan oleh perusahaan dalam mengambil keputusan agar dapat bertahan dan kompetitif. Penelitian ini dilakukan bertujuan untuk menginvestigasi pengaruh dari ketidakpastian pada kebijakan trade credit perusahaan Indonesia. Hasil penelitian ini menunjukkan bahwa ketidakpastian mengurangi receivable days dan payable days yang dimiliki perusahaan. Hal ini menunjukkan bahwa perusahaan menyesuaikan kebijakan trade creditnya agar dapat bertahan didalam keadaan ketidakpastiaan yang tinggi dan terhindar resiko kendala keuangan di masa depan.

Berdasarkan dari hasil penelitian ini, kami menemukan bahwa manajer pada perusahaan Indonesia terpengaruh pada ketidakpastian ekonomi. Hasil penelitian ini menunjukkan bahwa manajer memutuskan untuk mengurangi penggunaan hutang dagang (account payable) maupun memberikan piutang kepada pelanggan (account receivable). Akan tetapi, manajer perlu mempertimbangkan bagaimana hal ini dapat berakibat pada operasional perusahaan di masa depan, seperti yang kita ketahui bahwa hutang dagang membantu perusahaan untuk mendapatkan fleksibilitas operasional dan account receivables dapat meningkatkan hubungan jangka panjang dengan pelanggan, yang pada akhirnya dapat mempengaruhi nilai perusahaan (Jory et al., 2020).

Penelitian ini memiliki keterbatasan yaitu antara lain: (1) sampel yang digunakan hanya perusahaan terbuka; (2) pengukuran uncertainty yang digunakan hanya ukuran yang dikembangkan oleh Ahir et al. (2018) sehingga tidak dapat melakukan robustness test dengan menggunakan pengukuran uncertainty lain. Hasil penelitian ini juga menghasilkan beberapa saran untuk penelitian 
selanjutnya. Pertama, penelitian selanjutnya diharapkan agar dapat melakukan penelitian lanjut untuk mengetahui perbedaan antara ketidakpastian pada level dunia dan level negara. Kedua, penelitian selanjutnya juga akan menjadi menarik untuk menambah lingkup observasi penelitian pada negara lainnya untuk dapat melakukan perbandingan antar negara yang memiliki karakteristik yang berbeda.

\section{Daftar Pustaka}

Ahir, H., Bloom, N., \& Furceri, D. (2018). The World Uncertainty Index. SSRN Electronic Journal.

Białek-Jaworska, A., \& Nehrebecka, N. (2016). The role of trade credit in business operations. Argumenta Oeconomica, 37(2), 189-231.

Bloom, N., Floetotto, M., Jaimovich, N., Saporta Eksten, I., \& Terry, S. (2018). Really Uncertain Business Cycles. Econometrica, 86(3), 1031-1065.

Cheng, N. S., \& Pike, R. (2003). The trade credit decision: Evidence of UK firms. Managerial and Decision Economics, 24(6-7), 419-438.

Gulen, H., \& Ion, M. (2016). Policy uncertainty and corporate investment. Review of Financial Studies.

Hoechle, D. (2007). Robust standard errors for panel regressions with crosssectional dependence. Stata Journal.

Jory, S. R., Khieu, H. D., Ngo, T. N., \& Phan, H. V. (2020). The influence of economic policy uncertainty on corporate trade credit and firm value. Journal of Corporate Finance, 64(August 2019), 101671.

Kozeniauskas, N., Orlik, A., \& Veldkamp, L. (2018). What are uncertainty shocks? Journal of Monetary Economics, 100, $1-15$.

Leahy, J. V., \& Whited, T. M. (1996). The Effect of Uncertainty on Investment: Some Stylized Facts. Journal of Money, Credit and Banking, 28(1), 64-83.

Li, X., \& Su, D. (2020). How does economic policy uncertainty affect corporate debt maturity?

MIAN, S. L., \& SMITH, C. W. (1992). Accounts Receivable Management Policy: Theory and Evidence. The Journal of Finance, 47(1), 169-200.

Ozturk, E. O., \& Sheng, X. S. (2018). Measuring global and country-specific uncertainty. Journal of International Money and Finance, 88, 276-295.

Petersen, M. A., \& Rajan, R. G. (1997). Trade credit: Theories and evidence. Review of Financial Studies.

Phan, D. H. B., Sharma, S. S., \& Tran, V. T. (2018). Can economic policy uncertainty predict stock returns? Global evidence. Journal of International Financial Markets, Institutions and Money, 55, 134-150.

$\mathrm{Xu}, \mathrm{Z}$. (2020). Economic policy uncertainty, cost of capital, and corporate innovation. Journal of Banking and Finance, 111. 